\title{
Does the body orientation of waggle dance followers affect the accuracy of recruitment?*
}

\author{
David TANNER, Kirk VISSCHER
}

Entomology Department, University of California, Riverside CA 92521, USA

Received 22 September 2008 - Revised 30 September 2008 - Accepted 1 October 2008

\begin{abstract}
The honey bee waggle dance is a cascade of behaviors used to advertise the availability of a resource, and communicate its location. Little is known, however, about the behaviors of dance follower bees that allow them to extract information from the dance. We test competing hypotheses that suggest that either follower bees must be located behind a dancer bee or to the side of a dancer bee to be able to extract information from the dance. We also test if behaviors relating to the time that a follower bee spends following a dance are important in collecting dance information. We find that the bees are equally efficient finding a resource indicated by the dance after following a dance from the side or behind a dancer bee. We also find that the number of waggle runs followed has a significant effect on the accuracy of a foraging flight.
\end{abstract}

honey bee / Apis mellifera / waggle dance / dance follower behavior

\section{INTRODUCTION}

Honey bees are able to communicate the direction of a resource to a nest mate using a series of behaviors known as the waggle dance (von Frisch, 1967). Direction is communicated in the dark interior of a hive on the surface of vertical honey comb by returning foragers walking a straight line relative to "up" at the same angle that was flown to arrive at the resource relative to the sun's azimuth (Fig. 1). The distance of a resource is communicated in the duration of the waggle phase, which correlates to its distance from the hive (Wenner, 1962, reviewed by von Frisch, 1967). While the mechanics of the dance and its varied dialects are well understood, little is known about what behaviors dance followers perform to facilitate the transfer of information. Some data suggest that the angle of a follower bee's body relative to that of the dancer affects the

Corresponding author: D. Tanner, dtanner@biology.usu.edu

* Manuscript editor: Stan Schneider efficiency of interpreting the location of the resource (Bozic and Valentincic, 1991; Judd, 1995). Bozic and Valentincic (1991) report that bees located to the side of a dancer bee remain in contact longer than those that locate behind, and they suggest that the direction to the resource is received through antennal contact by the follower bee with the dancer bee's body.

Conversely, Judd (1995) suggested that only follower bees behind the dancer bee are successful at acquiring sufficient information to arrive at the indicated resource. In this experiment, Judd noted where all follower bees were located relative to a dancing bee advertising a feeder offering a rich sucrose solution, and reported that only bees that followed the dancer bee within a $30^{\circ}$ arc behind the midline of her abdomen were successful at locating the feeder. The feeder in Judd's study, however, was located $150 \mathrm{~m}$ from the hive, a distance that is close relative to the range over which honey bees typically forage (Visscher and Seeley, 1982), producing dances that were 


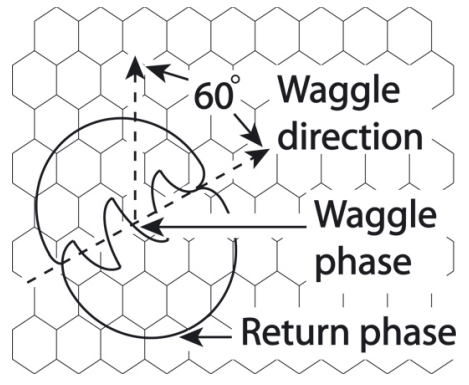

Figure 1. Waggle dance of the honey bee. The direction to a resource, relative to the sun's azimuth, is encoded in the dance as the angle of a waggle phase relative to "up" in the hive. In this figure, a recruit has performed a waggle phase $60^{\circ}$ to the right of "up", communicating that the resource is located $60^{\circ}$ to the right of the sun's azimuth.

both spatially and temporally short relative to the returning paths. Consequently, bees following short dances may have had too little time to orient during the waggle phase of the dance and spent proportionally longer to the rear of the dancer while she was transitioning between consecutive waggle phases. The methods employed by Judd (1995) not withstanding, this "follow behind" hypothesis is supported by many studies showing that information is communicated by dancer bees using near field sound emitted by the wings to follower bees that are oriented close behind abdomen of a dancer bee (Michelsen et al., 1987, 1992; Rohrseitz and Tautz, 1999; Kirchner 1993; Michelsen, 2003).

In this study, we identify the behaviors that aid in the collection of dance information by examining the dance following behaviors of successful recruits. Namely, we quantified the location and orientation of follower bees relative to a dancer bee, with three alternative hypotheses in mind: (1) the "follow behind" hypothesis, suggested by Judd (1995), that states following behind the dancing bee is necessary for a recruit to successfully acquire information from the dance and find the resource, or at least that bees that follow behind are more accurate at finding the indicated resource, (2) the "follow beside" hypothesis, suggested by Bozic and Valentincic (1991) which states that following beside the dancing bee is necessary for a recruit to successfully acquire dance information from the dance, or at least that bees that follow from the side are more accurate at finding the indicated resource, and (3) the "follow any side" hypothesis, which states that bees acquire information from the dance equally well whether they follow dances from the side or behind. Additionally, to test if behaviors other than the relative orientation of the dance follower bees are important, we quantified the amount of time follower bees spent in antennation, the number of waggle phases followed, the mean time spent following, and the total time spent in proximity to a dancer bee during the last bout of uninterrupted waggle phases. We used only the data that were collected from the last dance bout that a bee followed for this analysis, because previous studies have shown that bees do not integrate multiple dance bouts into a single flight vector (Gould, 1975). We then performed a multiple regression analysis between these variables and used the lateral displacement from the indicated resource as the dependent variable.

\section{METHODS}

To determine which behaviors performed by dance followers are important in collecting dance information, we conducted an experiment in which a small number of individually marked bees were trained to forage at a feeder offering a rich sucrose solution located at the center of an array of traps. These bees returned to the hive and danced to advertise the feeder to a colony of individually marked bees. Recruits that followed the dance and attempted to locate the indicated resource were captured in one of the traps along the array. We used the angular displacement of each recruit from the center of the array along the trap line as an index of how accurate she had been in interpreting the direction indicated in the dance.

\subsection{Colonies and observation hive}

We used two colonies of bees in this experiment. Each bee, in both colonies, was marked with a colored plastic tag (green, red, white, yellow, or blue) numbered between 00 and 99 on her thorax and an acrylic paint mark (blue, green, red, 


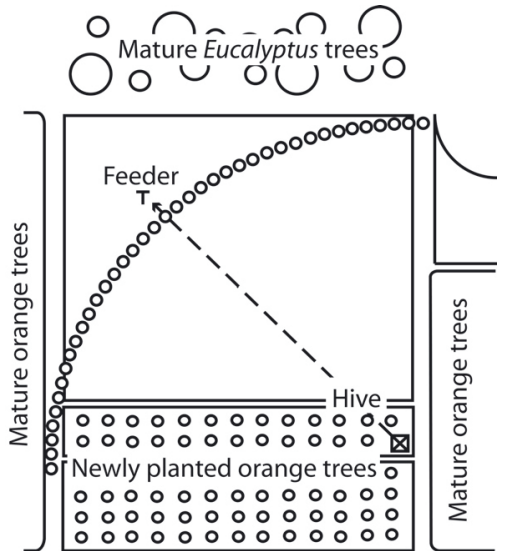

Figure 2. Arial view of trap array. The hive was located adjacent to a grove of newly planted orange trees. The traps and feeder were located in a field of newly planted alfalfa. Data were collected from the first colony in December 2, 2005 between 1100 and 1530 . The mean daytime temperature was $14{ }^{\circ} \mathrm{C}$ and the wind speed was $5 \mathrm{kph}$ out of the NNW $\left(300^{\circ}\right)$. Data from the second colony were collected on January 9, 2006 between $0830 \mathrm{am}$ and $1530 \mathrm{pm}$. The mean daytime temperature was $16^{\circ} \mathrm{C}$ and the wind speed was $19 \mathrm{kph}$ from the NNW $\left(300^{\circ}\right.$ ) (weather data from instruments on the Experiment Station site where the study was conducted).

or white) on the tip of the abdomen, which also sealed the Nasanov gland. Nasanov glands were sealed to ensure that only dance information and nectar odor were used to arrive at the a trap, and not pheromones. The marked bees were introduced into an observation hive consisting of two frames of comb containing both brood and food. The sides of the hive were covered with panes of glass so that the bees could be observed. The entrance to the hive was fitted with a wedge that directed all incoming bees to one side of the frame, so that all dances could be videotaped.

To allow ambient light to illuminate the surface of the hive for photography, we housed the hive in a $1.5 \times 1.5 \times 2 \mathrm{~m}$ wood hut consisting of three walls and a roof (one wall was missing to admit light). To prevent the bees using celestial polarized light as a reference for dancing, which can increase dance precision, we covered the hut with a $3 \times 3 \mathrm{~m}$ canopy with opaque sidewalls (von Frisch, 1967; Tanner, 2003), which diffused the light and obscured patterns of polarization. We located the hive, hut, and canopy adjacent to a newly planted grove of orchard trees (Fig. 2).

\subsection{Traps}

To collect follower bees recruited to the feeder by the dancer bees, we constructed traps to visually and olfactorally mimic flowers (Fig. 3). Traps consisted of a yellow funnel shaped to resemble the petals of a flower (Fig. 3A), which also served as the entrance to the trap. We painted blue nectar guides on the petals of the funnel to direct the bees to the entrance hole. The funnel was attached to a $3.8 \mathrm{~L}$ paper canister that we lined internally with black paper to absorb light entering the trap (Fig. 3B). We placed an open Petri dish $(60 \times 15 \mathrm{~mm})$ containing rich $(2 \mathrm{M})$, heavily scented sucrose $(20 \mu \mathrm{L} / \mathrm{L})$ close to the interior end of the funnel inside the trap. The dish was supported on a $0.47 \mathrm{~L}$ paper canister (Fig. 3C). A large hole was cut into the top of the trap that led to a $0.47 \mathrm{~L}$ paper trapping canister (Fig. 3D). The bottom of the trapping canister was replaced with a mesh cone that prevented bees from leaving the trapping canister and reentering the trap (Fig. 3E), and the top was replaced with wire mesh to allow light into the trapping canister (Fig. 3F). Therefore, once a bee entered the trap and finished feeding, she would fly to leave the trap, directed by the light entering through the trapping canister, crawl through the mesh cone, and become captured.

We placed the traps on tables, which supported the traps $70 \mathrm{~cm}$ off the ground, in an arc $250 \mathrm{~m}$ from the hive. We used thirty-nine traps, one trap placed every $10 \mathrm{~m}$ along the array (angular separation of $2.3^{\circ}$ ), for a total array length of $390 \mathrm{~m}$.

\subsection{Training to traps}

Bees are not very efficient at entering traps unless they have been trained to do so (Towne, 1985). To train bees to access the traps, we placed a trap near the hive on a tripod table, connected the trap to the entrance hole with a $1 \mathrm{~m}$ bridge of acrylic, and placed a trail of sucrose leading from the hive to the Petri dish of sucrose in the trap. We removed the lid from the trapping canister of a trap so that once a bee entered the trap and fed on the solution she would be able to return to the hive and recruit other bees to the trap. We also fitted the trap with a much larger entrance hole, consisting of a short length of PVC tube (internal diameter $3.17 \mathrm{~cm}$ ) fitted with artificial flower petals that were attached 


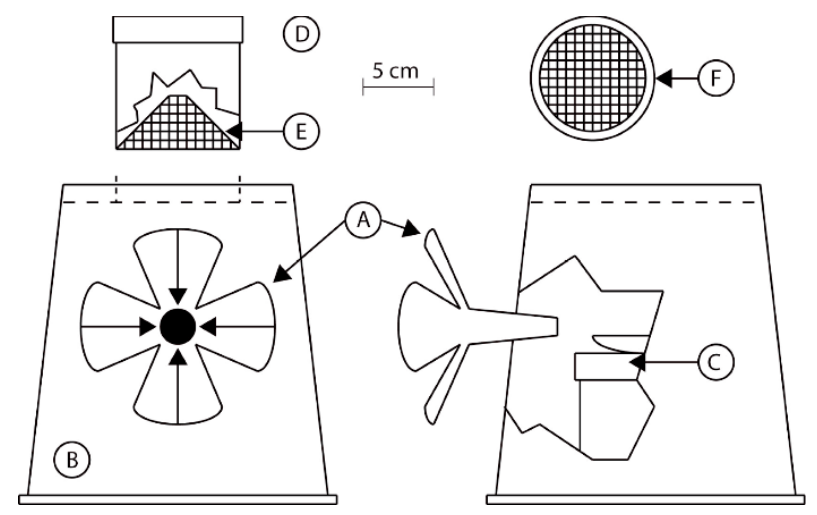

Figure 3. Schematic of trap. (A) Artificial flower and entrance to trap, (B) trap body, (C) pint paper canister supporting Petri dish of sucrose solution, (D) trapping canister, (E) wire mesh cone preventing recruits from reentering the trap, $(\mathrm{F})$ trapping canister lid.

with hot glue. Once bees were consistently climbing into the trap, the bridge was removed and the bees began flying to the trap. The training trap was left available to the bees for six hours on the day preceding the experiment and then was removed and not used in data collection. We supplied the training trap with a rich $(2 \mathrm{M})$ sucrose solution scented with peppermint oil $(15 \mu \mathrm{L} / \mathrm{L})$.

\subsection{Training to feeder}

We trained five bees to a feeder $260 \mathrm{~m}$ from the hive, past the center trap in the array, following standard techniques (von Frisch, 1967; Wenner, 1962). This group of bees danced during the experiment, communicating the direction of the center of the array to potential recruits. The feeder consisted of a $150 \mathrm{~mL}$ plastic canister with a slotted rim inverted over a plastic Petri dish. The feeder was supplied with a $2 \mathrm{M}$ sucrose solution scented with $15 \mu \mathrm{L}$ anise oil/L of sucrose. We maintained the number of bees visiting the feeder at 5 ; all excess bees were dispatched. Trap training and feeder training overlapped, but trap training did not begin until the feeder was $50 \mathrm{~m}$ from the hive.

\subsection{Data collection}

Prior to each replicate, we supplied the traps with $2 \mathrm{M}$ sucrose solution heavily scented with anise oil $(25 \mu \mathrm{L} / \mathrm{L})$. All traps were oriented such that the artificial flowers were directed toward the observation hive. And we made the feeder inconspicuous by placing it low to the ground and supplying it with a sucrose solution weakly scented $(2 \mu \mathrm{L} / \mathrm{L})$ with anise oil.

We recorded bee dances with a Sony handycam DCR-HC20 digital camcorder. When a single bee was dancing, which occurred most of the time, the camera was focused on the dancing bee and those directly around her. When there were multiple bees dancing, the dances of all bees were recorded simultaneously in a wider frame. Occasionally, when videotaping the dances of multiple bees, the numbers on tags could no longer be resolved. When this occurred we marked the location of all dances on the glass of the hive, and when a dance concluded we briefly videotaped the dancer and surrounding bees to record their identity. In this way, we were able to keep an accurate record of which bees followed the dances that were being performed for the feeder.

During each replicate, an observer walked close behind the trap line and exchanged any trapping canisters in which bees had become trapped with empty ones. The observer did not linger at a single trap for longer than 10 seconds. The time and trap location was noted for each canister, and placed in a large cooler that was then sealed tightly. No bees were released after entering the traps. All bees that were trapped during the experiment were kept to visually check against bees appearing on the videotape. 
Table I. Directional error of recruits. Data collected from bees at the Agricultural Research Station on the University of California Riverside. Negative errors indicate traps to the left of the feeder, and positive errors indicate traps to the right of the feeder.

\begin{tabular}{cc}
\hline Bee & Error in recruitment \\
\hline YY00 & -20.7 \\
GR12 & -18.4 \\
YR99 & -11.5 \\
BB30 & -9.2 \\
BW62 & -9.2 \\
RR64 & -9.2 \\
BB53 & -9.2 \\
YB24 & -6.9 \\
RW51 & -6.9 \\
YW16 & -4.6 \\
GW89 & -2.3 \\
YG11 & -2.3 \\
GG00 & 0 \\
GR55 & 0 \\
YR09 & 0 \\
YG32 & 0 \\
GG72 & 2.3 \\
YY73 & 4.6 \\
RW66 & 6.9 \\
YY01 & 9.2 \\
RR00 & 13.8 \\
BY60 & 18.4 \\
GW67 & 18.4 \\
BW67 & 20.7 \\
GB76 & 27.6 \\
\hline
\end{tabular}

\subsection{Video analysis}

We viewed all video using iMovie software on a Mac iBook laptop. When a bee that had been captured in a trap appeared on the screen, we measured the time spent in antennation, the total number of waggle phases followed per dance bout (defined as an uninterrupted series of waggle phases by a single dancer), the amount of time each bee spent in following (quantified as the amount of time a follower bee spent directed toward and within one antennal length from a bee performing a waggle phase), the amount of time spent behind the dancer (quantified as the amount of time a follower bee spent with some body part, commonly the antenna, across a posterior extension of the midline of the abdomen and directed toward the dancer), and the amount of time spent to the side or in front of the dancing bee (quantified as the amount of time a follower bee spent directed toward a bee performing a waggle phase without some body part extended to the posterior projection of the midline of the abdomen).

\subsection{Statistical analysis}

To test if the orientation of the follower bee, relative to that of the dancer bee, affects the accuracy of the foraging flight, we conducted a Spearman's rank correlation between the proportion of time each captured recruit spent following a dancer from behind and the accuracy of her foraging flight (i.e. displacement along the trap array from the feeder). The bees in this analysis were ranked from the least $(0 \%)$ to the greatest $(65 \%)$ proportional time spent behind the dancer. These bees were also ranked according to their accuracy in the foraging flight. Bees that made the smallest error in flight (i.e. arriving in traps close to the feeder) received smaller ranks than those that made large errors in recruitment. Thus, the "follow behind" hypothesis would predict a negative correlation, the "follow beside" hypothesis would predict a positive correlation, and the "follow any side" hypothesis would predict no correlation.

Also, to test if an orientation of a follower bee's body produced foraging flights of greater accuracy, we compared the accuracy of the foraging flight of bees that did not follow behind a dancer bee during the last waggle dance she followed prior to leaving the hive to the bees with the greatest time following behind a dancer using a t-Test. In this study, there were nine bees that did not follow a dancer from behind. Here, hypothesis 1 would predict smaller offsets from the resource in the follow behind group, hypothesis 2 would predict the opposite, and hypothesis 3 would predict no difference.

To test for other behaviors that a dance follower performs that allow her to collect information from the dance, we compared the amount of time follower bees spent in antennation, the number of waggle phases followed, the mean time spent following, and time spent in proximity to the dancer during the last dance bout of uninterrupted waggle phases that she followed to the log of the accuracy of their foraging flights using a multiple regression analysis. 


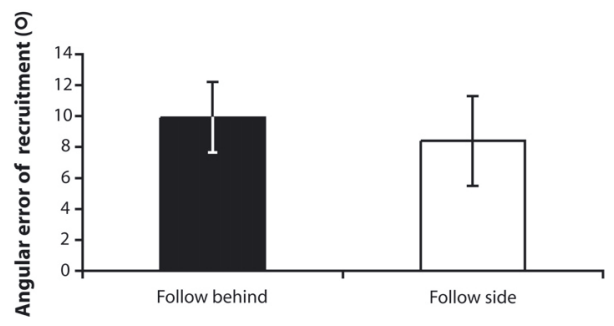

Figure 4. Effect of follower bee orientation on accuracy of foraging flight. Bins represent the mean angular error in recruitment (i.e. angular displacement from feeder), and the error bars are $95 \%$ confidence intervals.

\section{RESULTS}

\subsection{The effect of dance follower orientation on recruit accuracy}

Table I lists the accuracy of each bee recruited to the feeder and captured in a trap. A negative "error in recruitment" value indicated bees captured in traps to the left of the feeder from the hive, and positive values indicate bees captured to the right of the feeder.

The results of the Spearman's rank correlation shows that there is a slightly positive relationship between the time spent to the rear of the dancing bee and the error of her foraging flight, though this relationship is not significant $(\rho=0.1683, P>0.2)$. The t-test showed that bees that follow dances behind a dancer make slightly larger navigational errors $\left(9.9^{\circ} \pm 2.3\right)$ than those that do not $\left(8.4^{\circ} \pm 2.9\right)$, though this difference was also not significant $(\mathrm{t}=0.402, P>0.5$, Fig. 4).

\subsection{Are there other behaviors that are important?}

The results of the multiple regression analysis shows that of the four variables tested, only the number of waggle phases followed has a significant relationship with the accuracy of recruitment. The first step of the analysis regressed the number of waggle phases against the accuracy of dances $\left(\mathrm{R}^{2}=.1823\right.$, $P=0.0333$ ), and was the only significant step in this analysis. The second step added the total time spent in antennation $\left(\mathrm{R}^{2}=0.1940\right.$,
$P=0.0933)$, the third step in this analysis added the total time spent in proximity to the dancer $\left(\mathrm{R}^{2}=0.2268, P=0.1371\right)$, and the final step added total time spent following the dancer to the model $\left(\mathrm{R}^{2}=0.2275\right.$, $P=0.2479$ )

\section{DISCUSSION}

Our data show that acquiring enough dance information in order to arrive at a resource advertised in the dance does not require that follower bees orient behind a dancer bee. In this study, 9 of 25 that were successfully recruited to the traps never followed behind a dancer while she was performing a waggle phase. No follower bees in this study, however, were successfully recruited to the feeder without orienting, for even a short period of time, to the side of a dancer bee. Similar to previous studies, we found that bees began following dances near the head and thorax and concluded toward the abdomen (Rohrseitz and Tautz, 1999). These data do not, however, suggest that information from the dance is collected better from the side of the dancer. Indeed, we found no difference in the accuracy of recruitment between bees that spend the most proportional time oriented behind a dancer and bees that were not oriented behind a dancer during the last dance followed prior to a successful foraging flight. These data suggest that information from the dance may be collected whenever a follower bee is in close proximity to the dancer, regardless of how she orients her body.

These data also suggest that there may be other behaviors that are important in dance following. The only significant model generated by the multiple regression analysis was a one parameter model that included the number of waggle phases followed, suggesting that increasing the number of waggle phases followed, or perhaps the time followed, increases the accuracy of recruits' subsequent flights, which corroborates previous findings (Mautz, 1971). Coupled with the observations of Bozic and Valentincic (1991), bees that locate to the side of the dancer remain in contact with the dancer longer than those that locate to the rear 
of the dancer, providing some support for the "follow beside" hypothesis.

These findings are consistent with the averaging hypothesis for dance interpretation (Tanner and Visscher, 2008), which states that information from multiple waggle phases is incorporated into a single flight vector by a dance-following bee, using a cognitive process akin to averaging. The contribution of a single value decreases as more values are averaged; consequently, a vector calculated from a small number of waggle phases will more likely be affected by an aberrant waggle phase (which occurs from time-to-time in most dances) than one calculated from more waggle phases. Collectively, the variables that we tested explain $23 \%$ of the variation in recruit accuracy. This may improve somewhat with a larger sample of bees, however we feel that much of the variation in recruit accuracy may be explained by how a honey bee executes information collected from the dance, which is becoming more tractable as bee flight tracking equipment and studies are refined.

Even after many years of research, many aspects of the waggle dance remain a mystery. Due to its complexity, and the number of individuals vying for position around a dancer bee, dance followers are able to acquire only a fraction of the total information encoded in the dance. In this study, we show that while the relative orientation of follower bees has little to no effect on their ability to access information in the dance, the time spent following has a significant effect on the accuracy with which recruits are capable of locating the indicated resource.

L'orientation du corps des suiveuses dans la danse frétillante affecte-t-elle la précision du recrutement?

Apis mellifera / danse frétillante / recrutement / abeille suiveuse / communication animale

\footnotetext{
Zusammenfassung - Wird die Genauigkeit der Rekrutierung durch die Körperorientierung der Nachtänzerinnen beeinflusst? Der Schwänzeltanz der Honigbienen dient erfolgreichen Sammlerinnen dazu, den Nestgenossen den Ort einer Futterstelle mitzuteilen. Es ist allerdings nur sehr wenig über Verhaltensweisen
}

der Nachtänzerinnen bekannt, mit denen diese die Informationsübertragung erleichtern. Einige Angaben weisen darauf hin, dass die Nachtänzerinnen sich seitwärts der Tänzerinnen positionieren um die Tanzinformation zu erhalten (Bozic and Valentincic, 1991), während andere Autoren vorschlagen, dass die Bienen sich hierzu innerhalb eines $30^{\circ}$ Winkels hinter den Tänzerinnen aufhalten müssen (Judd, 1995). Um zu testen, ob die Orientierung der Körperachse der Nachtänzerinnen relativ zu der der Tänzerinnen für die Übertragung der Tanzinformation von Wichtigkeit ist und ob Verhaltensweisen während der Zeit, die die Bienen darauf verwenden einer Tänzerin zu folgen die Übertragung der Tanzinformation signifikant beeinflussen führten wir ein Experiment durch, in dem eine kleine Anzahl trainierter Bienen Nachtänzerinnen auf einen Zuckerfütterer zentral hinter einer Reihe von Fallen anwarben (Abb. 2). Nachtänzerinnen, die versuchten eine Futterstelle aufzufinden, wurden in den Fallen gesammelt (Abb. 3), und der Irrtum des Anwerbewinkels (Winkelabweichung von der Richtung zur Futterstelle entlang der Fallenreihe) wurde als Erfolgsindex für die Aufnahme der Tanzinformation genutzt. Wir erfassten zusätzlich die Dauer der Zeit, die Nachtänzerinnen mit Fühlerkontakt verbrachten, die Anzahl der verfolgten Schwänzelläufe, die durchschnittliche Dauer der Tanzverfolgung und die während der letzten Folge ununterbrochener Schwänzelläufe in der Nähe einer Tänzerin verbrachte Gesamtzeit. Wir ermittelten, dass die Körperorientierung der Nachtänzerin relativ zu der der Tänzerin die Genauigkeit des Sammelfluges der Nachtänzerin nicht signifikant beeinflusst. Dagegen hatte die Anzahl der von einer Nachtänzerin verfolgten Schwänzelläufe einen signifikanten Einfluss auf die Genauigkeit der Sammelflüge.

\section{Honigbienen / Schwänzeltanz / Nachtänzerinnen / Nachfolgeverhalten}

\section{REFERENCES}

Bozic J., Valentincic T. (1991) Attendants and followers of honey bee waggle dances, J. Apic. Res. 30, 125-131.

Frisch K. von (1967) The dance language and orientation of bees, Harvard University Press, Cambridge Massachusetts.

Gould J.L. (1975) Honey bee recruitment: the dancelanguage controversy, Science 189, 685-693.

Judd T.M. (1995) The waggle dance of the honey bee: which bees following a dancer successfully acquire the information? J. Insect Behav. 8, 343354 .

Kirchner W.H. (1993) Acoustical communication in honeybees, Apidologie 24, 297-307. 
Mautz D. (1971) Der Kommunicationseffekt der Schwänzeltänze bei Apis mellifera carnica (Pollm.), Z. Vgl. Physiol. 72, 197-220.

Michelsen A. (2003) Signal and flexibility in the dance communication of honeybees. J. Comp. Physiol. A $189,165-174$.

Michelsen A., Towne W.F., Kirchner W.H., Kryger P. (1987) The acoustic near field of a dancing bee, J. Comp. Physiol. A 161, 633-643.

Michelsen A., Andersen B.B., Storm J., Kirchner W.H., Lindauer M. (1992) How honey bees perceive communication dances, studied by means of a mechanical model, Behav. Ecol. Sociobiol. 30, $143-150$.

Rohrseitz K., Tautz J. (1999) Honey bee dance communication: waggle run direction coded in antennal contacts? J. Comp. Physiol. A 184, 463-470.
Tanner D.A. (2003) An evaluation of the tuned-error hypothesis in the honey bee. MS thesis, University of California, Riverside.

Tanner D.A., Visscher P.K. (2008) Do honey bees average directions in the waggle dance to determine a flight direction? Behav. Ecol. Sociobiol. 62, 18911898.

Towne W. (1985) The spatial precision and mechanisms of the dance communication of honey bees: experimental and comparative studies, $\mathrm{PhD}$ Thesis, Princeton University Press, Princeton, NJ.

Visscher P.K., Seeley T.D. (1982) Foraging strategies of honeybee colonies in a temperate deciduous forest, Ecology 63, 1790-1801.

Wenner A.M. (1962) Sound production during the waggle dance of the honey bee Anim. Behav. 10, 79-95. 